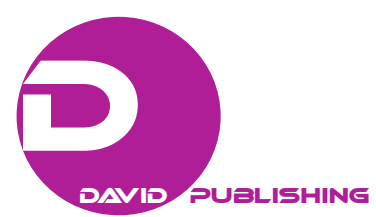

\title{
Features of EU Regional Economic Development and Georgia
}

\author{
Lali Chagelishili-Agladze \\ Guram Tavartkiladze Teaching University, Tbilisi, Georgia
}

\begin{abstract}
Main aim of EU regional policy is to narrow social and economic disproportions and sharp equalization of life levels between separate regions. In this direction in the first part of article, basic aspects of EU regional economic development are reviewed. Second part contains the issue of harmonization of regional development indicators of Georgia with Europe. In the form of conclusion the work mentions that it is impossible to develop regional economy in Georgia without determining regional social-economic priorities, processing programs, planning and making prognosis, where the right and targeted usage of compatible resources of regions should be made and accentuated. The aim of the study is to analyze the factors of influence on the development of region and determination of competitive index of the field in the region. To ensure the accuracy of the study, methods of empirical analysis and Ex-Post competitiveness were used. Due to the objectives of the study the structure of the work is formed as follows: Regional Policy of EU, Priority Directions, Conclusion, and References.
\end{abstract}

Keywords: backward countryside, regional competitiveness, endogenous potential

\section{Regional Policy of EU}

The problem of unequal development of EU member countries is acute issue and its solution becomes more and more complex due to unequal regional development. That's why EU strives for making regional policy which assists the attraction of EU peripheries to its historic kernel.

Regional policy is refined, effectively acting circle in EU. The basis of it is the allocation of material resources in EU peripheral and depressed regions. Nowadays 36\% of the entire consolidated budget of EU is designed for the overcoming of social-economic development infringements between various countries and regions.

The aim of the regional policy is to minimize that misbalance which creates the reason of emerging social conflicts, prevents social-economic development of entirely countries, or their separate parts, groups of countries (for example, like EU member-states).

After war during decades no regional policy methods have remained unchanged. In the beginning accent is made first of all on solution of social issues and more attention was paid to also economic issues. During some time solving regional problems not only government, but also private capital was attracted. From large-scaled programs they started to move on to solving local issues and yet, the main aim of regional policy remained unchanged. It lies in the equalization of the acutest social and economic disproportions and life levels between separate regions.

Lali Chagelishili-Agladze, doctor of Economic Sciences, prof., Business Admistration Faculty, Guram Tavartkiladze Teaching University, Tbilisi, Georgia.

Correspondence concerning this article should be addressed to Lali Chagelishili-Agladze, 5 Samghereti St, Tbilisi 0101, Georgia. 
Means which are used for eradicating central, regional and local governments, and regional differences of various countries, are rather diverse and their selections are conditioned by whole range of factors: social-economic condition of the country, type of public administration, internal problems, and aims of political parties in government and other.

\section{Priority Directions}

The improvement of so-called "grey" of retarded agricultural regions ones is prioritized in basic directions of regional policy of EU. These regions, which are characterized by an aging population, high unemployment, and lack of capital, have been less involved in scientific-technical revolution. The classic example of the mentioned is the south part of Italy which retards from the point of development industrial north of this country. In France, Aquitania, North-West, and Corsica belong to such regions; in Galicia, Spain, some regions of south and central part; in Great Britain, Northern Scotland.

Regional policy in such regions foresees tax privileges, organization of special funds (for example, "South cash-desk" in Italy), establishment of entrepreneurial, and social infrastructure through government's means, which in its turn in most cases determines "business climate" of region. Often in such regions large industrial enterprises are incorporated, and though recently together with industrialization of weakly developed regions, great attention is paid to the development of agriculture, tourism, and recreation.

Second direction of regional policy lies in "reanimation" of depressed regions. These are old industrial regions formed in XVIII-XIX centuries, during the period of still industrial transformation, mostly developed through coal, iron mining, and loom industry. During the period of scientific-technical revolution, the energetic transformation from oil to gas; black metallurgy from local to richer iron mining beyond the ocean; and transformation of loom industry from natural to artificial fibber, such regions were lead to economic fall and depression. The term itself "depressive region" was raised yet in 1929-1933 during the world economic crisis. But the retardation of regions was particularly revealed after War World II in the epoch of scientific-technical revolution. The population started to get older, and structural crisis and structural unemployment took place.

Structural crisis caused serious strike to the coal and iron mining pools, old loom regions of Europe. Regional policy in depressive regions as a rule includes the implementation of new and recent entrepreneurial fields closely related to the scientific-technical revolution in economies of these regions, changing the profile of enterprise, with change of specialization of work forces and establishment of branches of trans-national corporations.

Third direction of regional policy lies in preventing the increase of city and particularly capital cities' aglomeration's hypertrophy. In 60-70s such an increase was taking place as a result of which was followed by so-called "crisis of cities" the mass divulge of rich layers of population outside the city from central part of the cities which were conditioned by the Hygiene Sanitary worsened by life and polluted city environment, overcrowded transport, worsened apartment fund and so on.

That's why in this region the main task of the regional policy became the prevention of increasing "super-cities". This is achieved first of all through regional planning which has been widely used in France and Netherlands. The construction of new cities and companion-cities of London and Paris was large-scaled in Great Britain and France, which assist the discharge of city aglomeration. There are separate examples of 
making so-called aglomeration passve (restriction of new constructions in large cities) as well as active (vacating enterprises from such cities).

Fourth direction of regional policy lies in adjusting new resource regions having extreme natiral conditinos. Before War World II countries of West Europe could rely upon fuel-raw material of their colonies and half-colonies. That's why their interest towards Northern regions and Australia was episodic, related mainly to "Golden Fever" (Klondike and Calgary), as a result of which they often used to remain as only "City-Shades" after colony system ruined the interest of west countries increased towards the regions of new adjustment. Also, it clearly revealed the trife towards orientation on own resources of heavy industry and decrease of dependency on importing raw materials and fuel, as a result of the large-scaled adjustment of these regions which occupied argest territory-totally 18 billiards of sq.m.

Fifth direction of regional policy — development of tensely populated regions-it was found out that not so long ago when Scandinavian countries_-Finland and Sweden joined EU in 1995.

Observations clarified that the low incomes of population in most cases are characterized to rural regions weakly developed (Portugal, Greece, and Spain), for old depressive industrial regions, the fields of which are coal industry, black metallurgy, loom industry, and construction of ships (North England, Wales, several regions of Belgium, and North of Spain) or for regions which have unreasonable economic-geographic condition (for example, regions are rather remote from the center of economic activity).

High level of welfare of population is characteristic to the large high-urban territories: Paris aglomerations (Il de France) with $170 \%$ incomes compared to the middle level of EU, territories which border Milan (Lombardia, 135\%), Hamburg (198\%), Bremens (156\%), Great London (144\%), Brussels (175\%), and Copenhagen (140\%).

Based on the joint negotiation of EU member-states in regional policy of CIS, the following five basic aims are:

(1) Assistance of structural transformations and development of retarded regions. The average product rate of regions for one person is less than $75 \%$ of average figure of EU CIS. The list of regions is reviewed in every five years.

(2) Assistance of transforming depressive regions, bordering regions, their parts and development, including labor market and also including cities (aglomerations) where there is high level of unemployment and industrial development decreasing.

(3) Struggling against long-term unemployment. Here criterium is the number of people older than 25 years who are unemployed and seek for job for one year already.

(4) Assistance in the labor life negating youth: The criteria of selection-youngsters of older than 25 seeking for job.

(5) Assistance of making total rural political reforms distinguishing two independent reasons (5a and 5b).

5a) Development of agricultural manufacturing and modernization (making agricultural and timber production, processing, and selling).

5b) Assistance of developing agricultural regions.

EU Commission established criteria for revealing those regions which are assisted subject to aim 5b: a) more part of employed in agriculture comparing to average figure of CIS; b) low level of incomes in agriculture; c) low level of social-economic development, calculated on the basis of average rate of product. 
XXI century puts serious problems to EU regional policy. For regions, the wide economic system parts and the motive power of regional promotion are their competitiveness. Also success depends on such factors like infrastructure, ecology, quality of work force, scientific-research potential, and position of regional governments. The unity of these factors makes region more or less attractive for foreign investors and also creates available preconditions for mobilization of own potential. In other words the unity of these factors creates the competitiveness of region. Also it is necessary to consider that the inter-regional competition goes beyond the national state borders.

Such an attitude of regional policy of EU towards regional development means the mobilization of internal (endogene) potential. The ways of achieving such aims are already changed from issuing subsidies EU gradually moving on large-scaled events, whcih create available business and investment climate in region, and that is the assistance to increasing their competitiveness. The entire assciation agreement once more elicidated the necessity of mentioned policy which for achieving European economic figures, raises the potential of regions as the isue of agenda as the promotion of competitiveness and strengthening. From this point of view it is rather considerable and speechful for the results of entire registration of population of Georgia in 2014, from which the demographic picture of Georgia becomes clear.

As to November 5th 2014 the number of population of Georgia was 3,729,635 men which comparing to the result of registration of 2002 (4,371,535 men) is less by 14.7\% (641,900 men).

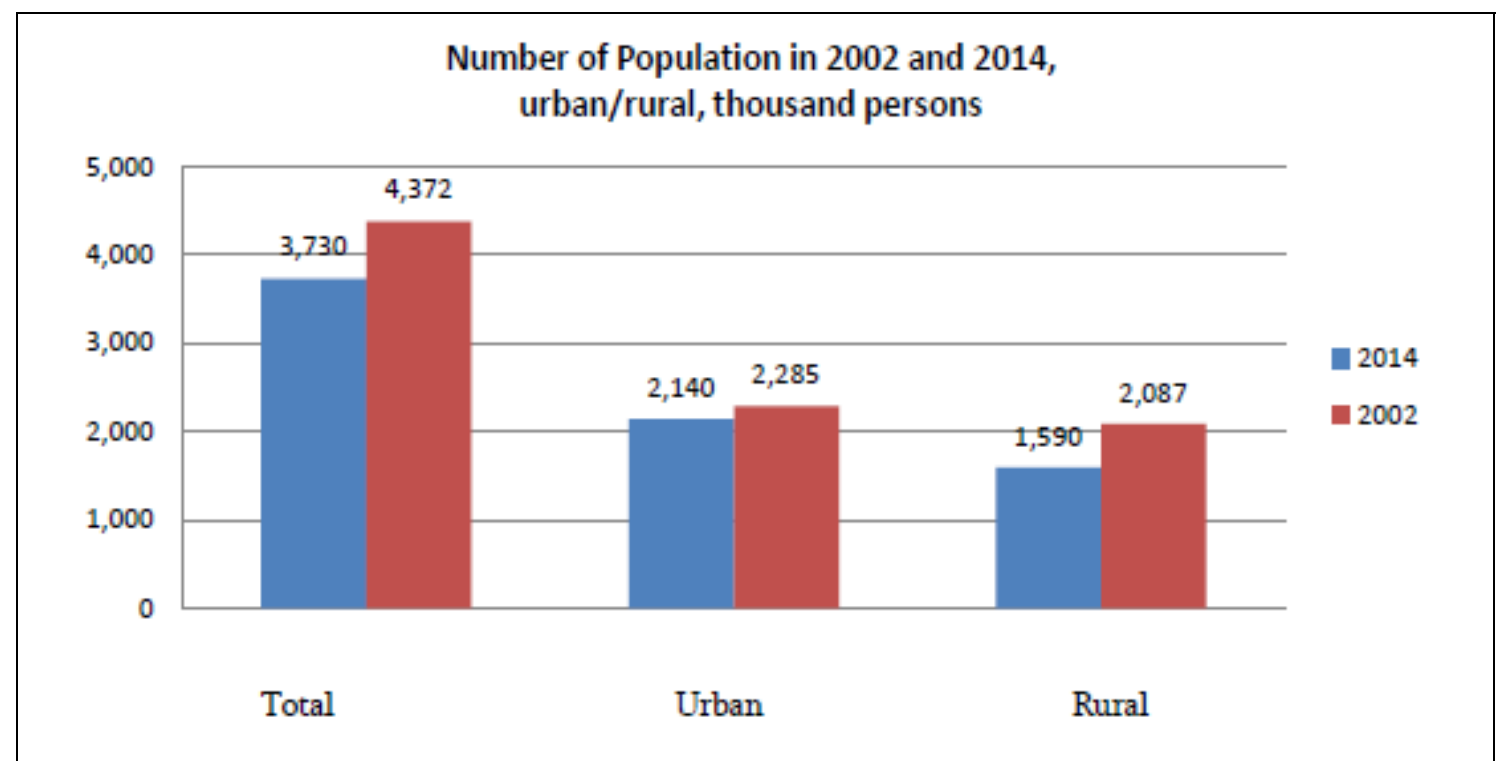

Figure 1. Number of population in 2002 and 2014, urban/rural, thousand persons (advance results of entire registration of population of Georgia in 2014).

In Figure 1, according to the results of registration of 2014, the city population included 2,140 men, and the country population 1,590 men. Decrease was basically faced by country population (23.8\%), and in the same period the city population was decreased (6.3\%). As a result, structure of city/country of previous registration has been changed significantly. Namely, $57.4 \%$ of whole population is the city population which is $5.1 \%$ more than relevant figure of previous registration. According to the advance results of entire registration of population of 2014 number of Tbilisi population is 1,118,035 men which comparing to previous registration is $3.4 \%$ more (this increase is basically conditioned by joining the settlements of country 
type of Mtskheta and Gardabani Municipalities to Tbilisi). Also it should be mentioned that the portion of Tbilisi population in entire population was increased by $5.2 \%$ and comprised $30.0 \%$. Increase is noticed in Batumi population (26.3\%), but increase in Batumi also was basically caused by amalgamation of settlements subordinated under Khelvachauri Municipality. Compared to the registration the most important increase (7.3\%) was determined in Rustavi and comprised 124,908 people (in the same limits as in 2002).

Table 1

Advance Results of Entire Registration of Population of Georgia in 2014

\begin{tabular}{llll}
\hline Region & 2014 & 2002 & \% increase comparing to 2002 \\
\hline Totally & $3,729,635$ & $4,371,535$ & -14.7 \\
Tbilisi & $1,118,035$ & $1,081,679$ & 3.4 \\
Autonomous Republic of Abkhazia & $\ldots$ & 1,956 & $\ldots$ \\
Autonomous Republic of Adjara & 336,077 & 376,016 & -10.6 \\
Guria & 113,221 & 143,357 & -21.0 \\
Imereti & 536,052 & 699,666 & -23.4 \\
Kakheti & 319,144 & 407,182 & -21.6 \\
Mtskheta-Mtianeti & 94,370 & 125,443 & -24.8 \\
Racha-Lechkhumi and Lower Svaneti & 31,927 & 50,969 & -37.4 \\
Samegrelo-Upper Svaneti & 331,145 & 466,100 & -29.0 \\
Samtskhe-Javakheti & 160,262 & 207,598 & -22.8 \\
Lower Kartli & 424,769 & 497,530 & -14.6 \\
Inner Kartli & 264,633 & 314,039 & -15.7 \\
\hline
\end{tabular}

In the section of region the most important decrease comparing to the registration of 2002 is in the regions of Racha-Lechkhumi and Lower Svaneti (37.4\%) and Samegrelo-Upper Svaneti (29\%) and the least in Autonomous Republic of Adjara (10.6\%). As of October 1st 2014 the number of family economies in the country was up to 640,302 .

As a result of agricultural registration of 2004, 728,247 family economies were determined. Also it should be noted that the agricultural economy registration of 2014 did not include five big cities: Tbilisi, Kutaisi, Rustavi, Batumi, and Poti.

Low quality of life and the reduction of population in rural areas of Georgia, also are due to investment which in the last period is improperly implemented and is reflected in the level of infrastructure in rural areas and rural social-economic situation.

Despite the general structure of agriculture, which is characterized by a growth rate of $8 \%$ in 2015 compared to 2014, according to individual sectors (production of vegetable crops, livestock products, and the production of dairy products) dynamics is unsatisfactory.

Wheat, tobacco, sugar, and poultry have important roles in the commodity imports of Georgia. These are the items that really have export potential but the use of it is not fully available. In the long term strategy above mentioned has a negative impact on competitiveness of the field. 


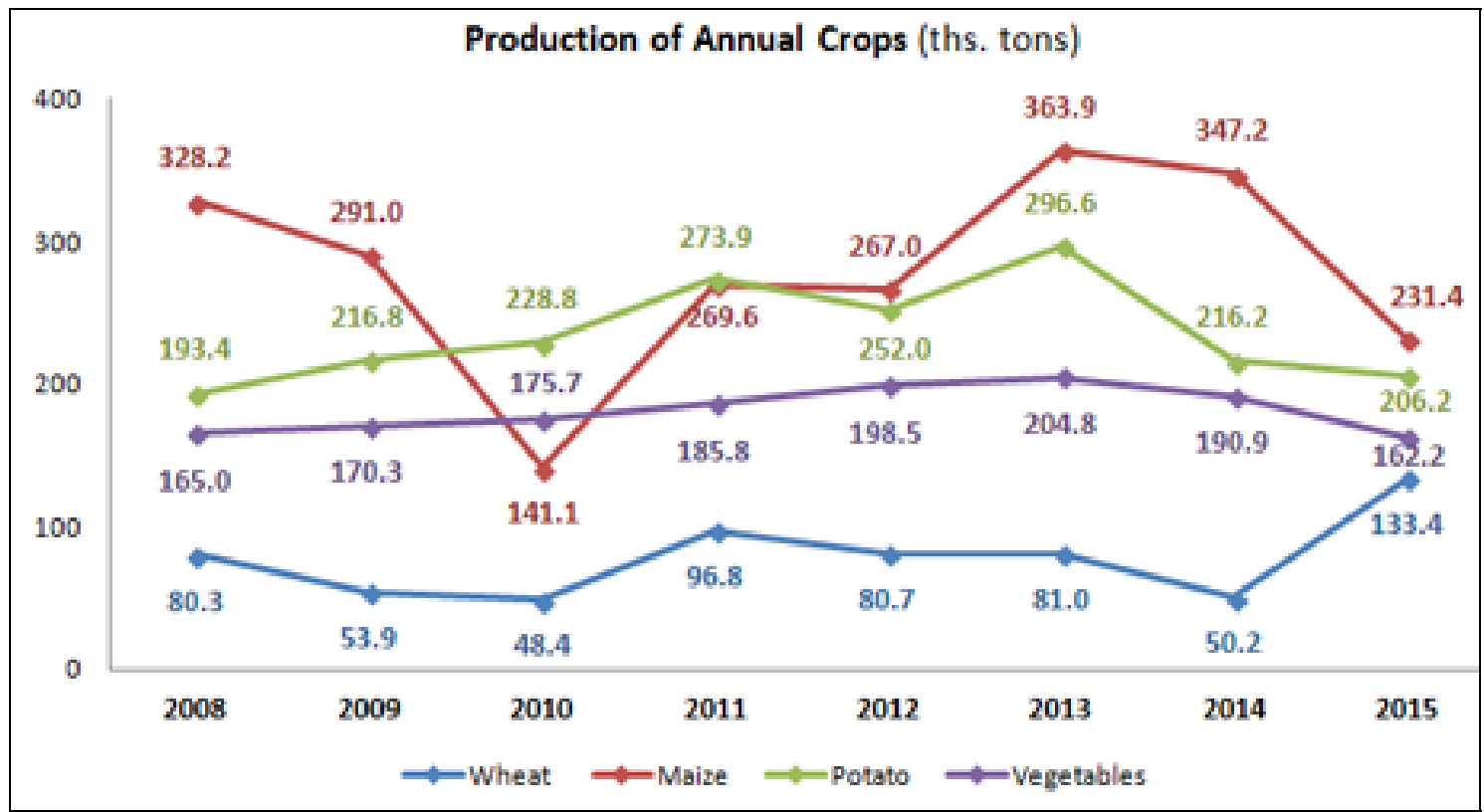

Figure 2. Production of annual crops [www.Geostat.ge-Agriculture, Environment and Food Security, 2016].

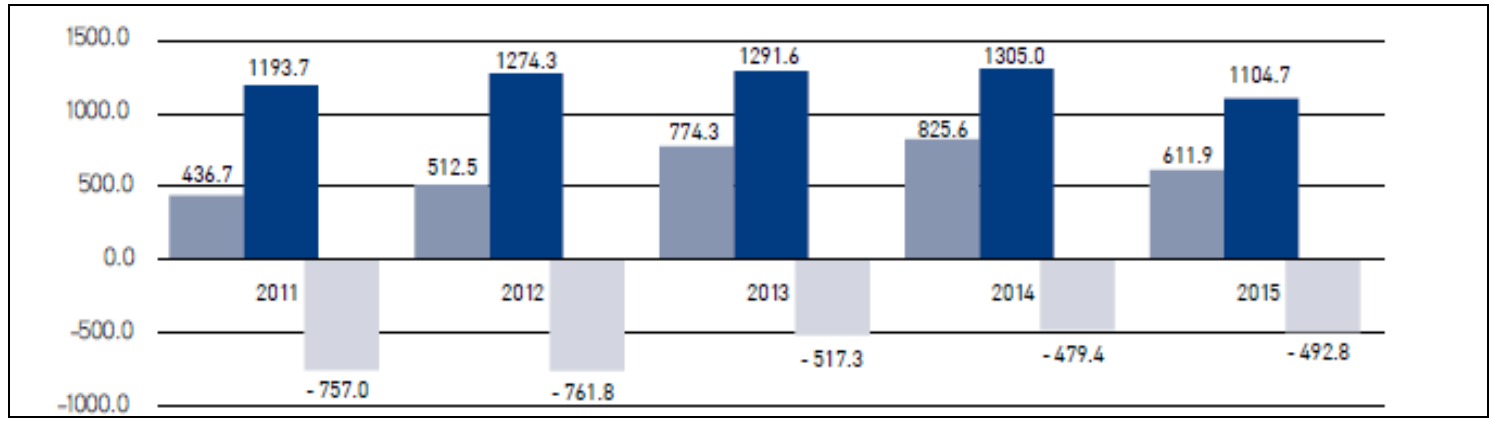

Figure 3. The Agro product export-import million USD (Ministry of Agriculture of Georgia, 2015, Annual Report).

With the use of the method of analysis of ex-post competitiveness (Wiknands \& Verhoog, 2016), the relative competitiveness index of rural agro-industrial potential was determined.

Table 2

Ex-post Competitiveness (Georgia)

\begin{tabular}{llllllll}
\hline Product & Indices & 2010 & 2011 & 2012 & 2013 & 2014 & 2015 \\
\hline \multirow{3}{*}{ Wine } & RXA & 47.4 & 46.5 & 45.9 & 44.7 & 46.7 & 46.9 \\
& RMP & 0.4 & 0.2 & 0.2 & 0.4 & 0.6 & 0.6 \\
& RTA & 47.0 & 46.3 & 45.7 & 44.3 & 46.1 & 46.3 \\
\multirow{3}{*}{ Nut } & RXA & 65.1 & 67.4 & 57.1 & 55.2 & 54.0 & 53.0 \\
& RMP & 21.0 & 16.7 & 15.8 & 15.0 & 10.7 & 10.0 \\
\multirow{3}{*}{ Crops } & RTA & 44.1 & 50.7 & 41.3 & 40.2 & 43.3 & 43.0 \\
& RXA & 16.5 & 16.7 & 10.5 & 9.8 & 7.2 & 7.1 \\
& RMP & 12.7 & 13.2 & 12.1 & 12.9 & 13.1 & 13.1 \\
\multirow{5}{*}{ Livestock } & RTA & 3.8 & 3.5 & -1.6 & -3.1 & -5.3 & -6.0 \\
& RXA & 20.0 & 21.1 & 19.8 & 17.2 & 17.1 & 17.0 \\
\hline
\end{tabular}




\section{Conclusion}

Mentioned figures do not give the possibility of drawing optimistic conclusion of social-economic development of regions, because for stable economic of region it is necessary to have the increase of population capable of working which we cannot say about regions of Georgia. Even more, for stable development of agriculture and tourism in Georgia such regions are attractive like Racha-Lechkhumi, Svaneti, mountainous Adjara, and Samtskhe-Javakheti, where according to recent data there are rather low speeds of allocating family economies (Figure 4).

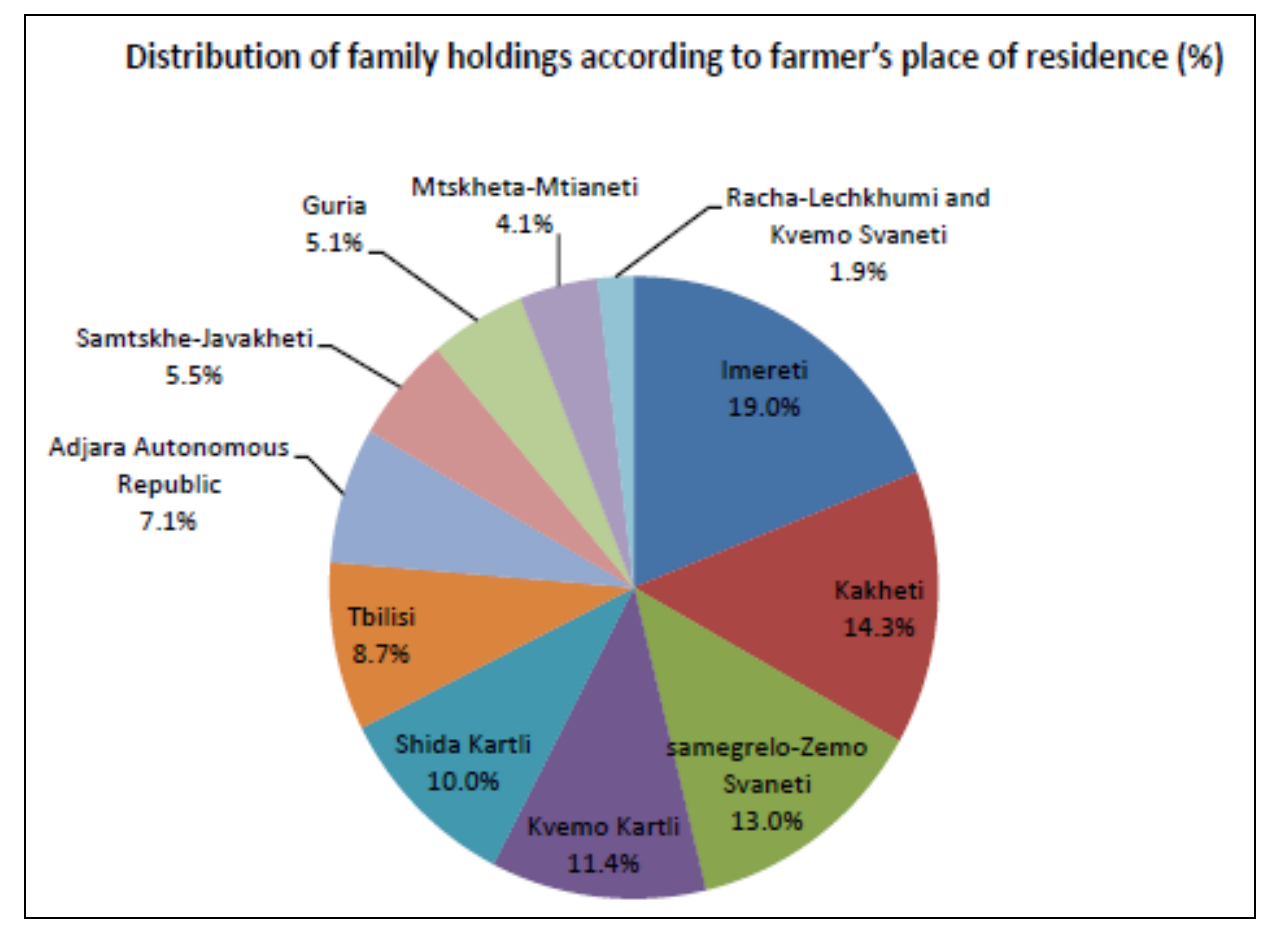

Figure 4. Distribution of family holdings according to farmer's place of residence (\%).

Due to the above mentioned, the Ministry of Regional Development and Economic of Georgia together with regional municipalities has serious work to do for implementing development programs of regions, making prognosis, and planning for perfectly using more competitive advantages of regions, for achieving harmonized social-economic characteristics to Europe and improving relative competitiveness index shown as the result of the study, especially in the direction of wine, nuts, cattle, and dairy production.

In this regard the Ministry of Agriculture should carry out investments in infrastructure projects, particularly:

- rehabilitation of roads in rural areas

- rural water supply

- support for the development of farming

- the development of the food processing industry

- providing quality control of agricultural products

These measures will contribute to the implementation of European standards and ensure the competitiveness of Georgian agricultural products to foreign markets, which will ultimately:

- increase the demand for Georgian export; 
- create jobs;

- provide coming back of rural population and forming economically active layer;

- ensure the effective use of resources and the development of regional tourism.

\section{References}

European Commission. (2005). Brussels, xxx SEC, 288/3. Commission Staff Working Paper. Annex to: "European Neighbourhood Policy”. Country Report, 3, 19-21. Georgia.

Local/Regional Economic Development in South-Eastern Europe. (2006). Concepts, instruments, and lessons learned. Deutsche Gesellschaft fur Technische Zusammenarbeit (GTZ) GmbH.

Ministry of Agriculture of Georgia. (2015). Annual Report.

National Statistics Office of Georgia(Geostat). (2014). General Population Census Main Results_release_ENG_2016.pdf.

National Statistics Office of Georgia (Geostat). (2016). Foreign Direct Investments 2016 in Georgia—Preliminary. www.Geostat.ge-Agriculture, Environment and Food Security, 2016

Wiknands, Jo H. M., \& Verhoog, D. (2016). Competitiveness of the EU food industry. Ex-post assessment of trade performance embedded in international economic theory. Wageningen LEI Wageningen UR. 